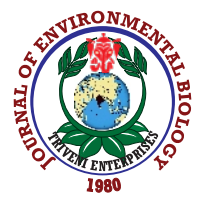

\title{
Evaluation of pathogenicity of indigenous entomopa- thogenic nematodes (Steinernematidae and Heteror- habditidae) from Mizoram, India, against tobacco cutworm, Spodoptera litura (Fabricius, 1775)
}

H.C. Lalramnghaki ${ }^{1,2}$, H.T. Lalremsanga ${ }^{2}$, Vanramliana', Lalramliana ${ }^{1 *}$, Vanlalhlimpuia ${ }^{3}$ and S. Lalliansanga ${ }^{4}$

${ }^{1}$ Department of Zoology, Pachhunga University College, Aizawl-796 001, India

${ }^{2}$ Department of Zoology, Mizoram University, Aizawl-796 004, India

${ }^{3}$ Department of Environmental Science, Aizawl-796 004, India

${ }^{4}$ Directorate of Agriculture (Research \& Extension), Aizawl-796 001, India

*Corresponding Author Email : Irl_zoo@yahoo.co.in

\section{Abstract}

Aim: To evaluate pathogenicity of locally isolated entomopathogenic nematodes Heterorhabditis indica, Heterorhabditis baujardi and Steinernema sangiagainst larvae of S. litura (Lepidoptera: Noctuidae).

Methodology: Different concentrations of nematodes (10, 25, 50, 100, 200, 400 and 800 infective juveniles per larva) of $H$. indica, $H$. baujardi and $S$. sangi were used against $3^{\text {rd }} 4^{\text {th }}$ and $5^{\text {th }}$ instar larvae of $S$. litura using Petri dish assay. Pathogenicity test was performed by assessing larval mortality of $S$. litura, penetration of infective juveniles and successive production of nematodes on the larvae of $S$. litura. $\mathrm{LC}_{50}$ and $\mathrm{LT}_{50}$ values were calculated by Probit Regression Analysis using SPSS software 20.0.

Results: All the tested EPN isolates showed high pathogenicity against the pest, with a strong positive correlation between nematode concentrations, inoculation time and larval mortality. Among the isolates, S. sangi showed highest pathogenicity against the pest by showing the lowest value of $\mathrm{LC}_{50}$ at $48 \mathrm{hr}$ post-inoculation $\left(9.2,55.58\right.$ and 350.65 infective juveniles for $3^{\text {rd }}, 4^{\text {th }}$ and $5^{\text {th }}$ instar larvae, respectively) and $\mathrm{LT}_{50}$ values $(24.52,34.13 \mathrm{and} 74.69 \mathrm{hr}$ against $3^{\text {rd }}, 4^{\text {th }}$ and $5^{\text {th }}$ instar larvae, respectively) at a dosage of 50 infective juveniles per larva. Besides, the nematodes were produced successfully inside the $5^{\text {th }}$ instar larvae of $S$. litura (57192.86 infective juveniles per larva for $S$. sangiand 72231.13 infective juveniles per larva for $H$. baujardi).

Interpretation: EPN isolates represent good candidates to control S. litura and can be considered for integrated pest management (IPM).

Key words: Biological control, Entomopathogenic nematodes, Infective juveniles, Integrated pest management, Spodoptera litura

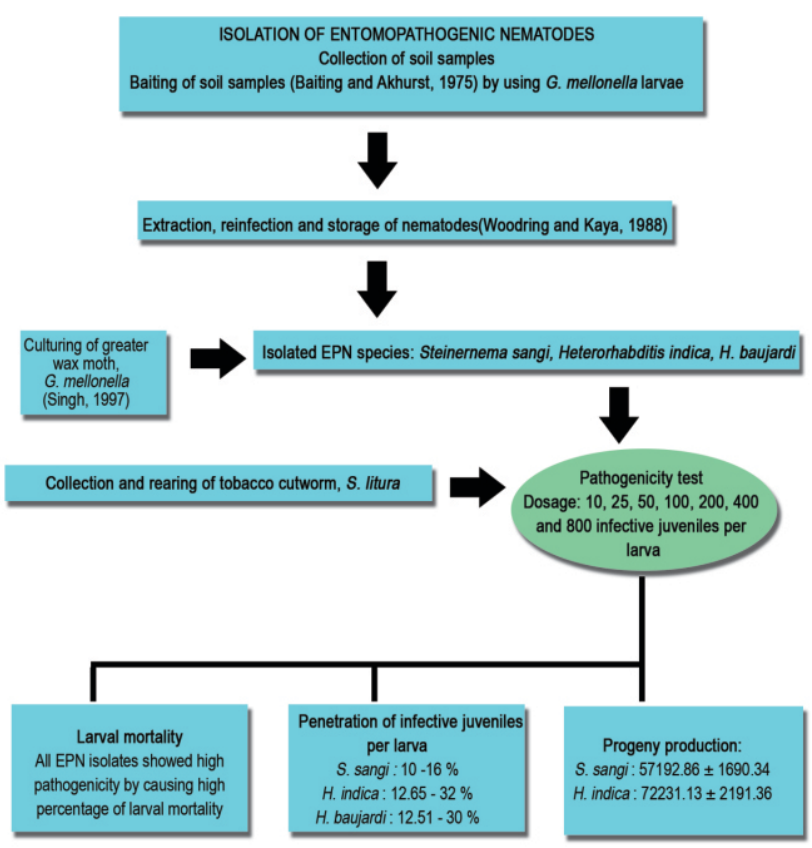

How to cite : Lalramnghaki, H.C., H.T. Lalremsanga, Vanramliana, Lalramliana, Vanlalhlimpuia and S. Lalliansanga: Evaluation of pathogenicity of indigenous entomopathogenic nematodes (Steinernematidae and Heterorhabditidae) from Mizoram, India, against tobacco cutworm, Spodoptera litura (Fabricius, 1775). J. Environ. Biol., 41, 851-860 (2020). 


\section{Introduction}

Tobacco cutworm (Spodoptera litura F.) is one of the most destructive and serious pests of agricultural crops with widespread distribution throughout tropical and temperate Asia, Australia and Pacific Islands (Feakin, 1973; Kranz et al.,1977). In India, it has a widespread distribution across the land, covering almost all the states (CABI, 2019) and responsible for heavy damage of economically important crops like groundnut (Patil et al., 1996), soybean (Choudhary et al., 2007; Punithavalli et al., 2014; Sharma et al., 2014), cotton (Gedia et al., 2008). The larva is a polyphagous pest (Singh and Jalali, 1997) and reported to infest different varieties of plants, including major agricultural crops such as tobacco, groundnut, taro and castor (Wu et al., 2004; Qing et al., 2006) causing an economic loss of about 26-100 percent on the fields (Dhir et al., 1992; Rao et al.,1993; Isman et al., 2007; Satyagopal et al., 2014).

Excessive use of chemical pesticides became a serious problem as insects have continued to show increased resistance against pesticides (Lohar et al., 1995; Kerns et al., 1998; Whalon et al., 2007). S. litura, in particular, has been reported to develop resistance against number of chemical pesticides viz., organophosphate, carbamate, pyrenoids and more towards newly developed chemical insecticides (Armes et al., 1997; Kranthi et al., 2002; Ahmad et al., 2007a, b; 2008; Saleem et al., 2008), resulting in ineffective management that leads to huge loss of agricultural crop production around the world (Ahmad et al., 2007a). Similarly, the harmful effects that chemical pesticides can impose on human health, non-targeted organisms and environment (Gaugler, 1988; Villani and Wright, 1988) need instant action. Therefore, the need for alternative methods of insect pest management has become an important issue and biological control is one of the most ideal alternatives for chemical pest management (Brixey, 1997).

Entomopathogenic nematodes (EPNs) of the genera, Steinernema Travassos, 1927 and Heterorhabditis Poinar, 1976 are obligate and lethal parasites of insects (Poinar, 1979) that are characterized by their symbiotic association with bacteria, Xenorhabdus spp. in steinernematids and Photorhabdus spp. in heterorhabditids (Poinar, 1990). EPNs naturally occur in soil and are reported to have widespread geographical and diverse climatic distributions across the globe (Hominick et al., 1996), except Antarctica (Hominick, 2002). The only considered freeliving stage of EPNs, infective juveniles (Boemare, 2002), after in contact with the insect host enter through body openings like spiracles, oral cavity, anus and also through cuticle in some cases (Bedding and Molyneux, 1982; Dowds and Peters, 2002). Upon entering the host insect, the infective juveniles release the intestinal harboured symbiotic bacteria and infected host insect dies within 24-48 hr of infection (Poinar, 1979). The infective juveniles may reproduce for about 2 to 3 generations inside the host, and later exit the nutrient depleted cadaver to infect new insect host in the soil (Kaya, 1990; Grewal and Georgis, 1999). In addition to the primary agents for host insect death, the symbiotic bacteria provide nematodes with nutrition and protection from other micro-organisms that may invade them (Poinar, 1990). With the urgent need for more sustainable eco-friendly strategy of pest management, EPNs have been developed and frequently applied for regulating and controlling of insect pests (Shapiro-llan et al., 2002 a; Georgis et al., 2006). The potential of EPNs as biological control agents differ with the process of invasion and evasion of host insects (Simões and Rosa, 1996), host age and nematode strain (Fuxa et al., 1988). For the successful development of EPN as suitable biological control agents, the locally adapted indigenous species of EPNs need to be evaluated where they show higher pathogenic potential against the host insect in comparison to non-native species (Bedding, 1990; Grewal et al., 2002; Lewis et al., 2006). In light of the above, the present study was conducted to study the pathogenicity of three species of EPNs, Steinernema sangi, Heterorhabditis indica and $H$. baujardi against tobacco cutworm, $S$. litura.

\section{Materials and Methods}

Nematode sources: Three species of EPN, S. sangi (Phan et al., 2001), H. indica (Poinar et al., 1992) and H. baujardi (Phan et al., 2003) were isolated from soil by baiting methods (Bedding and Akhurst, 1975). Soil samples were collected from riparian forest in Mizoram, Northeast (NE) India. A total of $400-500 \mathrm{~g}$ of soil samples were collected from a depth of $10-15 \mathrm{~cm}$ from each collection site (approximately $1 \mathrm{sq}$. m) and transported to the laboratory. The collected soil samples were baited immediately by using larvae of greater wax moth, Galleria mellonella, in a plastic container and kept at room temperature. Larval mortality was checked every $24 \mathrm{hr}$ for 10 consecutive days and dead larvae were kept in modified white trap following the method of Kaya and Stock (1997). Healthy G. melonella were infected again with the extracted infective juveniles, maintained at $28^{\circ} \mathrm{C}$ and only the infective juveniles which passed through the re-infection process were collected for further use. The extracted EPNs were stored in the form of infective juveniles with aerated water in an incubator at $12-15^{\circ} \mathrm{C}$.

Collection of S. litura: Eggs of $S$. litura were obtained from the Department of Agriculture (Research \& Extensions), Government of Mizoram, Aizawl and incubated at $28 \pm 2^{\circ} \mathrm{C}$ for hatching. The emerged larvae were reared using castor plant leaves and different larval stages $\left(3^{\text {rd }}, 4^{\text {th }}\right.$ and $\left.5^{\text {th }}\right)$ were used for evaluation of their susceptibility against the locally isolated EPNs.

Larval mortality bioassay : Experiment on larval mortality was performed using Petri dish assay following methods of Kaya and Stock (1997). Petri dishes (35 x $10 \mathrm{~mm}$ in diameter) were lined with Whatman filter paper No. 1. Different concentrations of nematodes $(10,25,50,100,200,400$ and 800 infective juveniles per larva) were selected for the assay. Each concentration of nematodes in $0.5 \mathrm{ml}$ of deionized water was introduced into the 
petri dish and allowed to settle for 30 mins. A single larva of healthy $S$. litura was selected, introduced into the petri dish containing pre-inoculated infective juveniles, sealed with parafilm and kept in an incubator at $28^{\circ} \mathrm{C}$. For each larval stage $\left(3^{\text {rd }}, 4^{\text {th }}\right.$ and $\left.5^{\text {th }}\right)$ of $S$. litura, eight replicas were set for each species of nematode and concentrations of infective juveniles. The experiment was repeated three times. A petri dish lined with filter paper and wetted with deionized water was kept as control for the assay. Mortality of larvae were checked after every $24 \mathrm{hr}$ for five consecutive days. The mortality was confirmed by colour change on the body and smell emanating from the dead cadaver of larvae caused by the symbiotic bacteria.

Penetration of infective juveniles : Dead larvae from the mortality bioassay were dissected after $48 \mathrm{hr}$ of mortality and the total number of infective juveniles that had penetrated the larva were counted under the microscope. This experiment was performed for different concentrations of nematodes at different larval stages of the insect pest for all the EPN isolates.

Production of infective juveniles : A dosage of 200 nematode infective juveniles per insect larva with $0.5 \mathrm{ml}$ of deionized water was introduced into a petri dish lined with Whatman filter paper No. 1 and allowed to stay for 30 mins. For each species of EPN, $3^{\text {rd }}$ instar larva of $S$. litura was introduced into a petri dish pre-inoculated with nematodes, sealed with a parafilm and incubated at $28 \pm 2{ }^{\circ} \mathrm{C}$. The dead larva was rinsed with distilled water and transfer individually in a modified white trap (Kaya and Stock, 1997) for reproduction of nematodes and emergence of infective juveniles. After successive reproduction, the total number of emerged infective juveniles were counted for 20-30 days. A total of eight replicas were set for each species of nematode for all the larval stages of $S$. litura and the experiment was repeated thrice. The same procedure was done for $4^{\text {th }}$ and $5^{\text {th }}$ instar larvae.
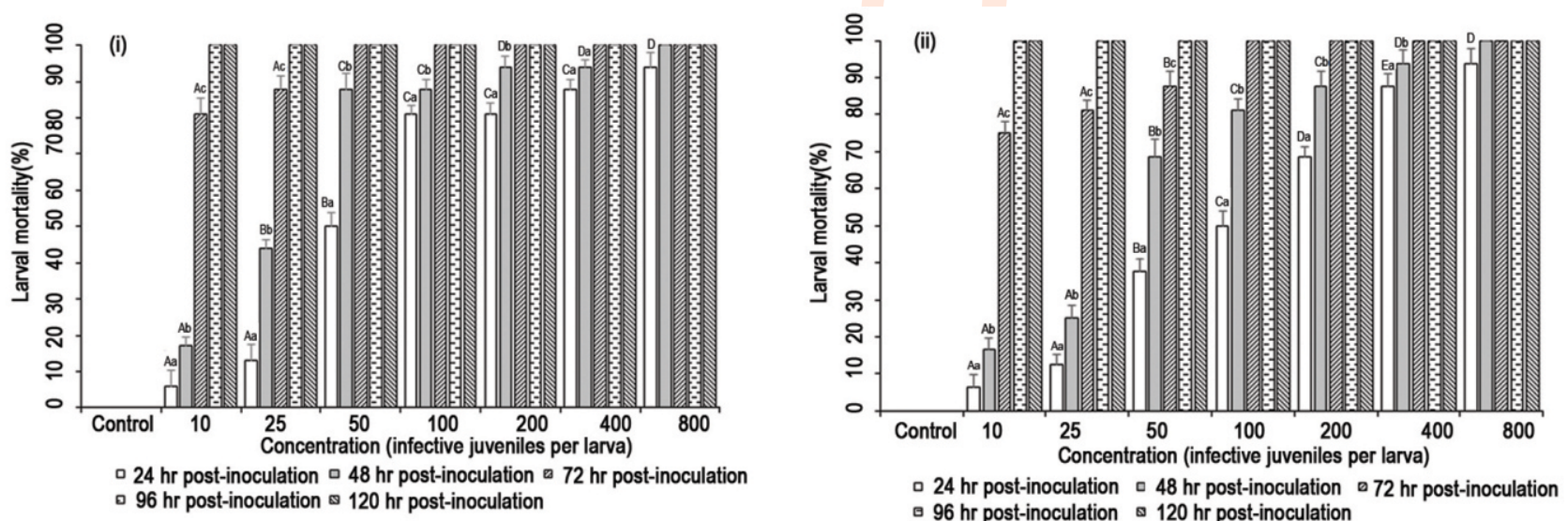

- $96 \mathrm{hr}$ post-inoculation $120 \mathrm{hr}$ post-inoculation

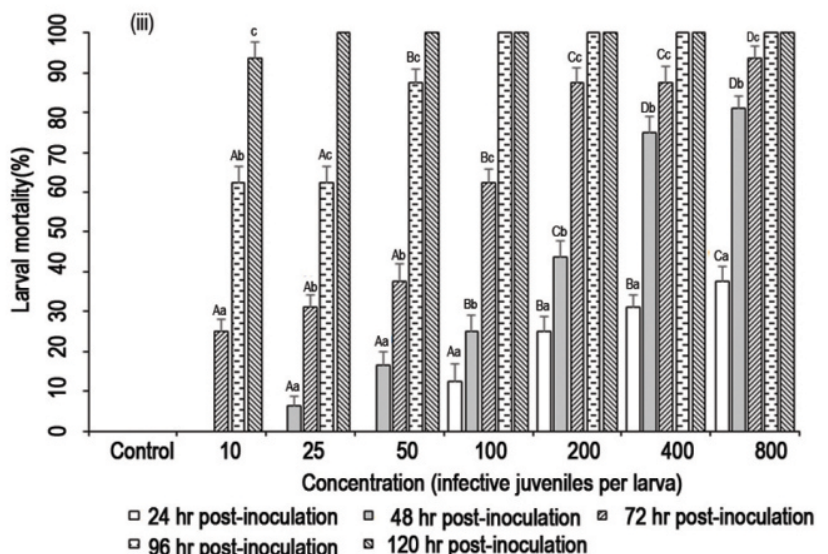

Fig. 1: Effect of different concentrations of $S$. sangi and incubation time on $S$. litura mortality (\% \pm S.E.). Vertical bars represent standard error of means. Bars with same uppercase letter indicates non-significant differences $(P>0.05)$ for different concentrations of $S$. sangi at same inoculation time. Bars with same lowercase letter indicates non-significant differences $(P>0.05)$ for same nematode concentration at different inoculation time. (i) Against $3^{\text {rd }}$ instar larvae, (ii) Against $4^{\text {th }}$ instar larvae and (iii) Against $5^{\text {th }}$ instar larvae. 


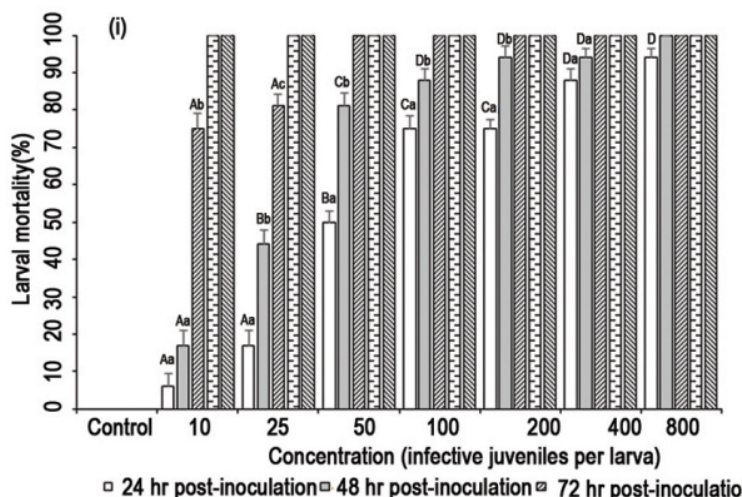

a $96 \mathrm{hr}$ post-inoculation $\otimes 120 \mathrm{hr}$ post-inoculation

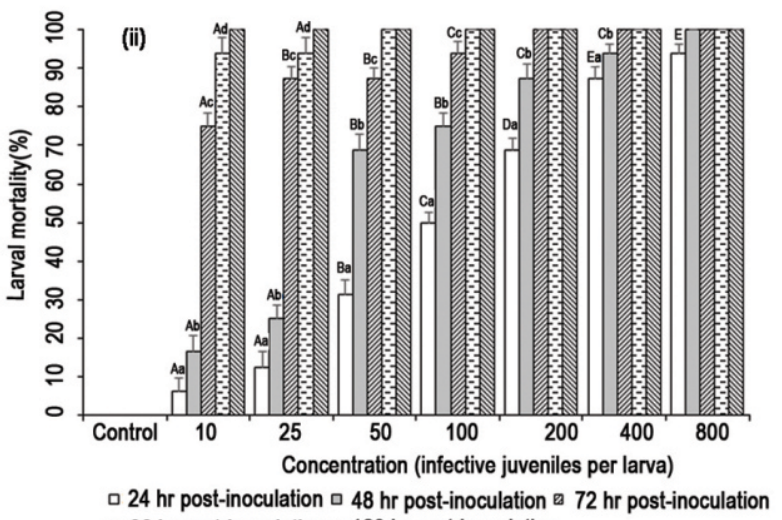

- $96 \mathrm{hr}$ post-inoculation $₫ 120 \mathrm{hr}$ post-inoculation

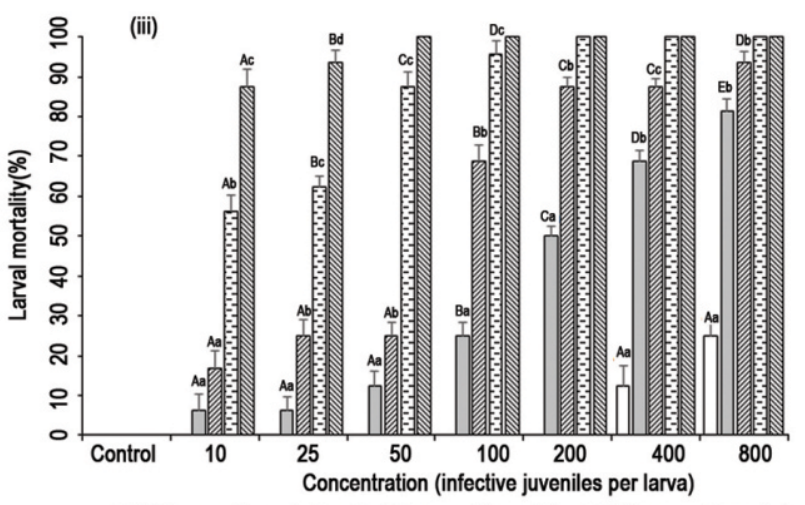

24 hrs post-inoculation $\square .48$ hrs post-inoculation $₫ 72$ hrs post-inoculation - $96 \mathrm{hrs}$ post-inoculation $₫ 120 \mathrm{hrs}$ post-inoculation

Fig. 2: Effect of different concentrations of $H$. indica and incubation time on S. litura mortality (\% \pm S.E.). Vertical bars represent standard error of the means. Bars with same uppercase letter stand for non-significant differences existing for different concentrations of $H$. indica causing $S$. litura mortality at same inoculation time. Bars with same lowercase letter stand for non-significant differences existing among different inculcation time causing $S$. litura mortality for same nematode concentration $(P>0.05)$. (i) Against $3^{\text {td }}$ instar larvae, (ii) Against $4^{\text {th }}$ instar larvae and (iii) Against $5^{\text {th }}$ instar larvae.

Statistical analysis : Statistical data analysis was performed for all the experimental data and were presented as mean \pm S.E. Student's t-test and One-way analysis of variance (ANOVA) were performed for analyzing significant differences at the level of $P \leq 0.05$. Probit Regression Analysis (using SPSS 20.0 software) was done to calculate the lethal concentration $(\mathrm{LC})_{50}$ and lethal time $(\mathrm{LT})_{50}$ values.

\section{Results and Discussion}

The results revealed that the three EPN isolates, S. sangi, $H$. indica and $H$. baujardi were highly pathogenic against $S$. litura larvae and the degree of pathogenicity showed significant variations with different concentrations of infective juveniles and incubation time (Fig. 1-3). However, no significant difference was observed among EPN isolates at same concentration of infective juveniles $(P \geq 0.05)$. Similar observation was reported by Phan et al. (2005) where a significant difference was observed between nematode isolates, concentrations of infective juveniles and exposure time to kill insect larvae.

At 50 infective juveniles per larva and $48 \mathrm{hr}$ post-inoculation, S. sangi showed the highest pathogenicity with $87.5 \%, 68.75 \%$ and $16.67 \%$ larval mortality against $3^{\text {rd }}, 4^{\text {th }}$ and $5^{\text {th }}$ larvae; $H$. indica showed $81.25 \%, 68.75 \%$ and $12.5 \%$ larval mortality against $3^{\text {rd }}, 4^{\text {th }}$ and $5^{\text {th }}$ instar larvae; and $H$. baujardi showed $81.25 \%, 62.5 \%$ and $16.67 \%$ larval mortality against $3^{\text {rd }}$, $4^{\text {th }}$ and $5^{\text {th }}$ larvae, respectively. Statistical analysis revealed significant difference in larval mortality of $S$. litura in the EPN isolates for different larval stages of $S$. litura $(F=1368.307$; $\mathrm{df}=2$, 93, $P<0.001$ for $S$. sangi, $F=1601.249$; $d f=2,93, P<0.001$ for $H$. indica and $F=912.064 ; d f=2,93, P<0.001$ for $H$. baujardi). However, no significant difference in larval mortality of the pest was found among the EPN isolates for same larval stages ( $F=$ 


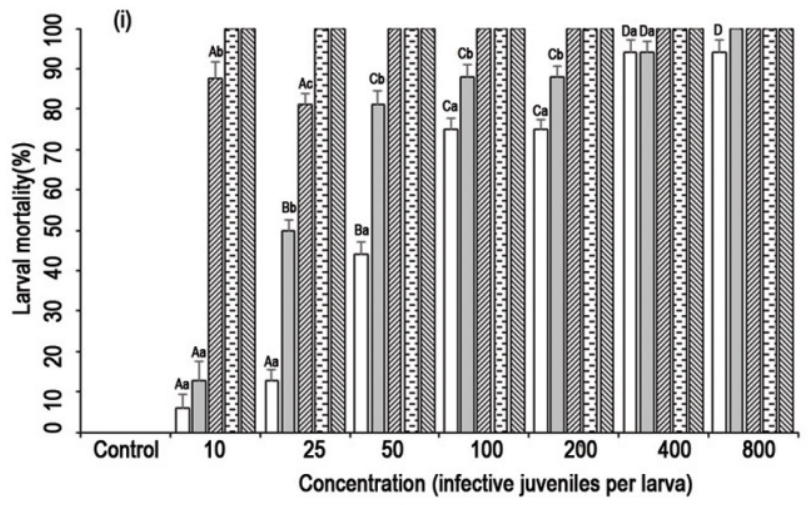

व $24 \mathrm{hr}$ post-inoculation a $48 \mathrm{hr}$ post-inoculation $\square 72 \mathrm{hr}$ post-inoculation - $96 \mathrm{hr}$ post-inoculation $8120 \mathrm{hr}$ post-innoculation

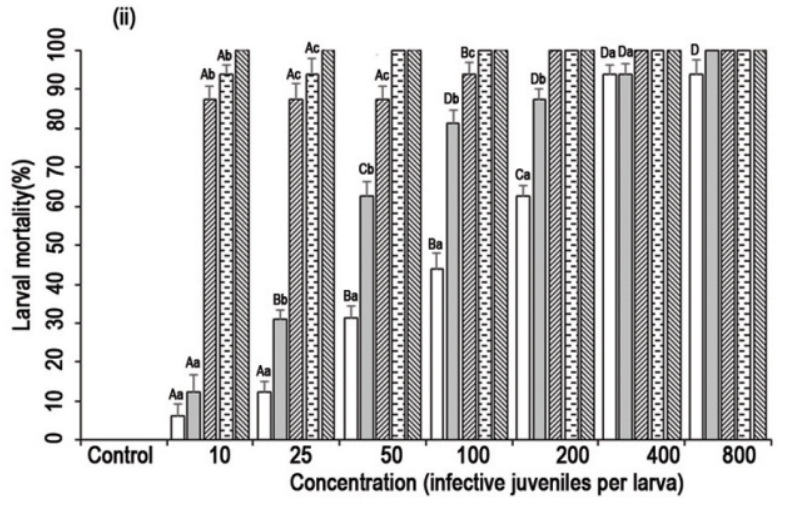

$\square 24 \mathrm{hr}$ post-inoculation $\square .48 \mathrm{hr}$ post-inoculation $\square 72 \mathrm{hr}$ post-inoculation - $96 \mathrm{hr}$ post-inoculation $\otimes 120 \mathrm{hr}$ post-inoculation

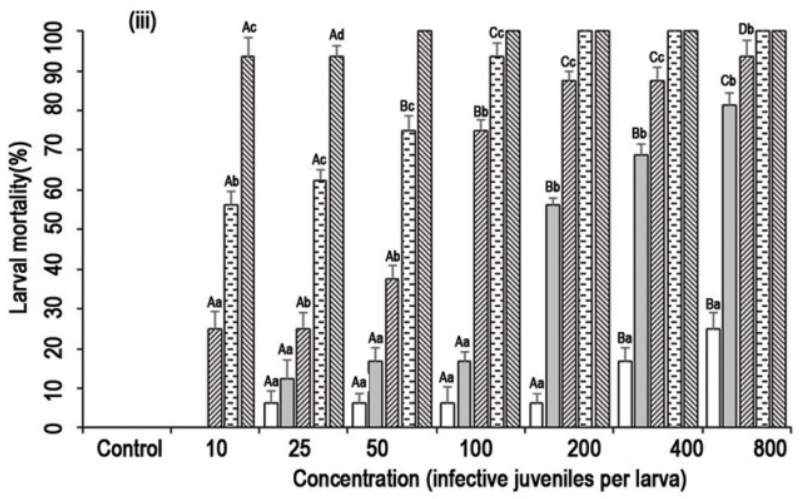

व $24 \mathrm{hr}$ post-inoculation a $48 \mathrm{hr}$ post-inoculation $₫ 72 \mathrm{hr}$ post-inoculation - $96 \mathrm{hr}$ post-inoculation \& $120 \mathrm{hr}$ post-inoculation

Fig. 3: Effect of different concentrations of $H$. baujardi and incubation time on $S$. litura mortality $(\% \pm S$.E.). Vertical bars represent standard error of the means. Bars with same uppercase letter stand for non-significant differences existing for different concentrations of $H$. baujardi causing $S$. litura mortality at same inoculation time. Bars with same lower-case letter stand for non-significant differences existing among different inculcation time causing $S$. litura mortality for the same nematode concentration $(P>0.05)$. (i)Against $3^{\text {td }}$ instar larvae, (ii)Against $4^{\text {th }}$ instar larvae and (iii)Against $5^{\text {th }}$ instar larvae.

368.307; $d f=2,93, P>0.05$ for $3^{\text {rd }}$ instar larvae, $F=307 ; d f=2,93$, $P>0.05$ for $4^{\text {th }}$ instar larvae and $F=298 ; d f=2,93, P>0.05$ for $5^{\text {th }}$ instar larvae). The result of laboratory evaluation demonstrated that all the EPN isolates were highly pathogenic against $S$. litura with more pathogenicity towards the $3^{\text {rd }}$ instar larvae.

Larval mortality time (hr): The recorded larval mortality time showed positive correlation with concentration of nematodes and duration of incubation $\left(r^{2}=0.88\right.$ in S. sangi, $r^{2}=0.97$ in $\mathrm{H}$. indica and $r^{2}=0.89$ in $H$. baujardi). Mortality of $3^{\text {rd }}$ instar larvae of $S$. litura was first observed at a concentration of 10 infective juveniles during $24 \mathrm{hr}$ post-inoculation (Fig.1-3). Similarly, 50 \% larval mortality was caused by both $S$. sangi and $H$. indica and $43.75 \%$ by $H$. baujardi at a concentration of 50 infective juveniles per larva during $24 \mathrm{hr}$ post-inoculation. After $48 \mathrm{hr}$ of incubation, absolute larval mortality of $S$. litura was observed at a concentration of 800 infective juveniles per larva for all the EPN isolates.
After $24 \mathrm{hr}$ of inoculation, larval mortality of $4^{\text {th }}$ instar larvae was initially recorded at a dosage of 10 infective juveniles for all the EPN isolates. With the same incubation time, larval mortality of $5^{\text {th }}$ instar larvae was first observed at 100 infective juveniles per larva which indicates that larval mortality continued to decrease with the advancement of larval stages of the pest. Furthermore, against $5^{\text {th }}$ instar larvae, S. sangi caused $100 \%$ larval mortality at 100 infective juveniles per larva and, similarly, at 200 infective juveniles per larva by both $H$. indica and $H$. baujardi.

$\mathrm{LC}_{50}$ and $\mathrm{LT}_{50}$ values were calculated for all the nematode isolates (Table 1, 2). At 50 infective juveniles per larva during 48 hr post-inoculation, the value of $L_{50}$ on $3^{\text {rd }}$ instar larvae was 9.2, 16.37 and 17.04 infective juveniles per larva for $S$. sangi, $H$. indica and $H$. baujardi, respectively. With the same concentration of infective juveniles, $S$. sangi showed less $L T_{50}$ value $(24.52 \mathrm{hr})$ in comparison to $H$. indica and $H$. baujardi $\left(\mathrm{LT}_{50}\right.$ values of 25.36 and 


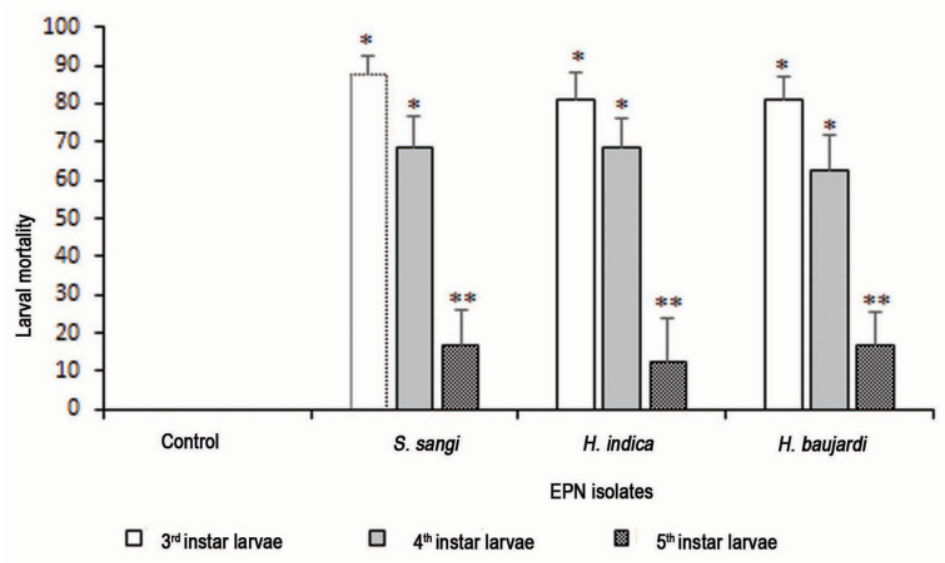

Fig. 4: Graph showing comparison of mortality ( $\%$ ) of different larval stages of $S$. litura at 50 infective juveniles per larva and $48 \mathrm{hr}$ post-inoculation ( $\% \pm$ S.E.). Vertical bars are standard error of means. * and ${ }^{* *}$ represent significant difference of larval mortality $(\%)$ at $P \leq 0.05$ and $P \leq 0.01$ level, among different larval stages for same nematode isolate.
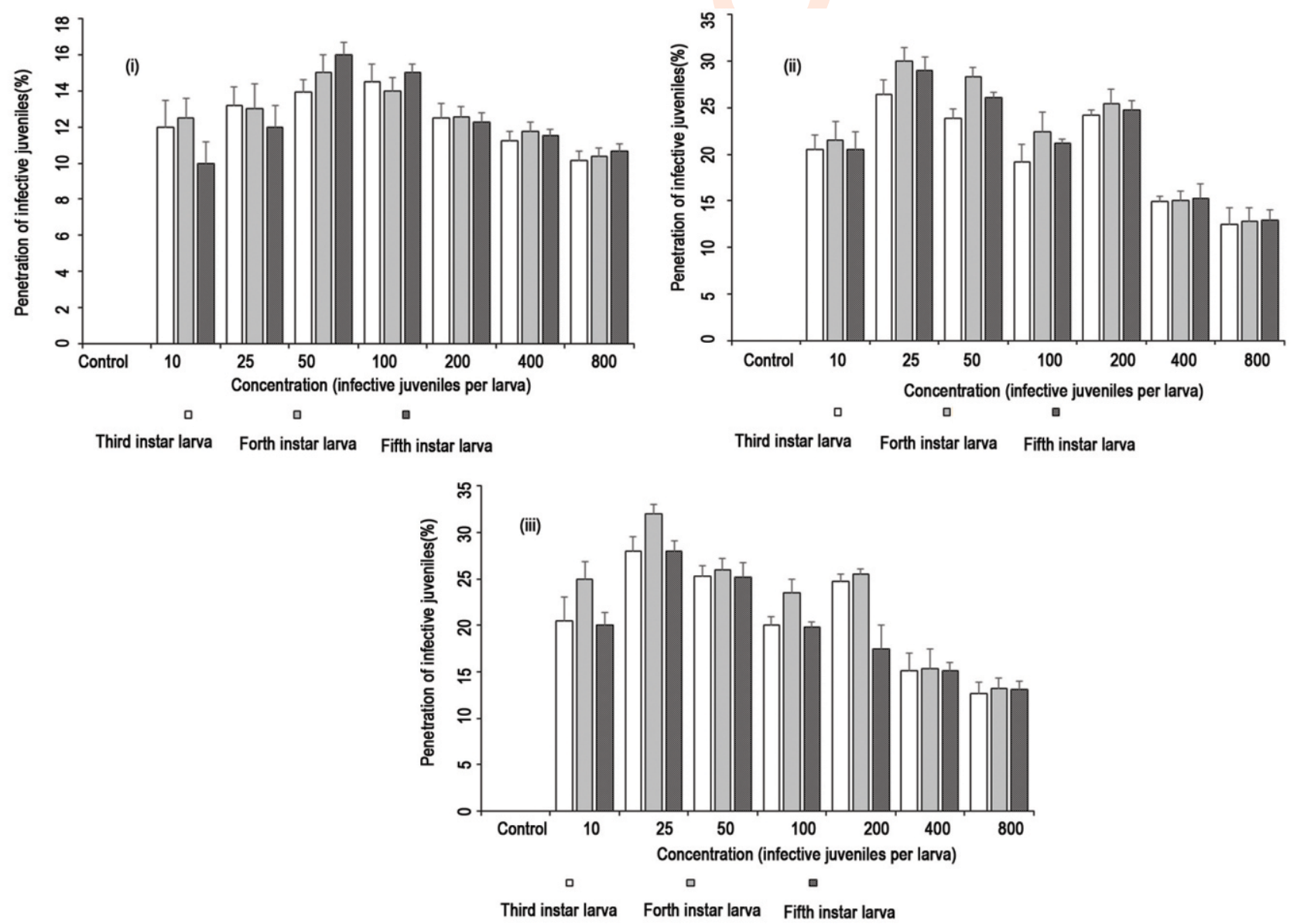

Fig. 5: Graph representing percent penetration of IJs for different concentrations of EPN isolates. Correlation analysis showed that total number of infective juveniles penetration into the pest larvae were positively correlated with nematode concentrations for all the EPN isolates $\left(r^{2}=0.95\right.$ for $S$. sangi, $r^{2}=0.97$ for $H$. indica and. $r^{2}=0.89$ for $H$. baujardi). However, no statistically significant variations exist for percentage penetration of infective juveniles for different concentrations of nematodes. (i) S. sangi, (ii) H. indica and (iii) H. baujardi. 


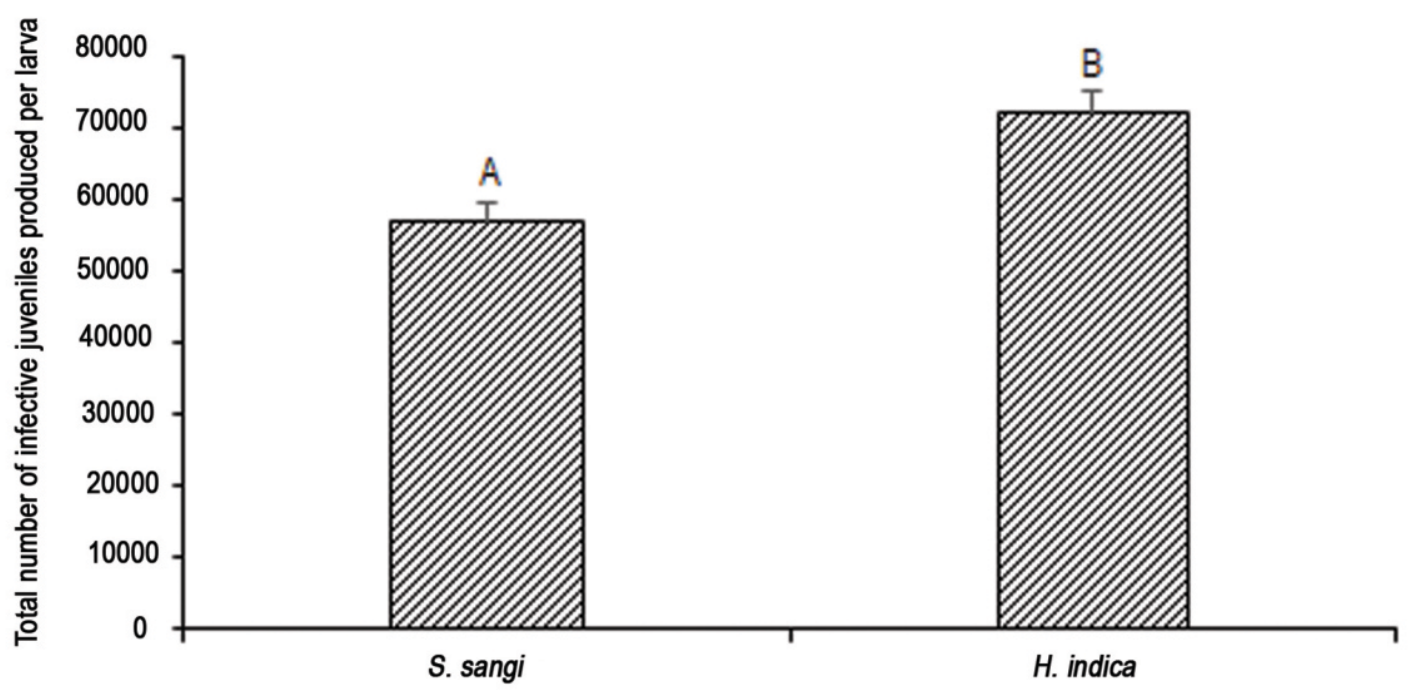

\section{EPN isolates}

Fig. 6: Production of infective juveniles in $5^{\text {th }}$ instar larvae of $S$. litura at a dosage of 200 infective juveniles per larva (Mean \pm S.E.). Bars with different uppercase letter stand for significant differences existing between $S$. sangiand $H$. indica at the level of $p \leq 0.01$.

$28.06 \mathrm{hr}$, respectively). S. sangi showed highest pathogenicity against $3^{\text {rd }}$ instar larvae of $S$. litura followed by $H$. indica and $H$. baujardi. Gokte-Narkhedkar et al. (2019) also reported LC $_{50}$ values of $H$. indica against $S$. litura larvae as 7.37-17.91 IJs at 48 $\mathrm{hr}$ of post-inoculation. In terms of $\mathrm{LC}_{50}$ and $\mathrm{LT}_{50}$ values, $\mathrm{S}$. sangi showed the highest pathogenicity against all the larval stages of $S$. litura with lowest $\mathrm{LT}_{50}$ and $\mathrm{LC}_{50}$ values. In addition, $H$. indica was more pathogenic against $3^{\text {rd }}$ and $4^{\text {th }}$ instar larvae but less pathogenic against $5^{\text {th }}$ instar larvae of $S$. litura as compared to $H$. baujardi. The result showed that $S$. sangi was most pathogenic against $S$. litura as it caused $93.75 \%$ mortality in $3^{\text {rd }}$ and $4^{\text {th }}$ instar larvae and $31.25 \%$ mortality at 400 infective juveniles per larva dose with $24 \mathrm{hr}$ of incubation. The observation is in concordance with Phan et al. (2005), who reported that 500 infective juveniles per larva dose of $S$. litoralis caused $92 \%$ larval mortality within 24 $\mathrm{hr}$ of incubation with $S$. sangi being the only isolate capable of causing larval mortality against all the evaluated pests.

Host penetration: The total number of infective juveniles that had penetrated the larva were recorded for different concentrations of nematodes for all the EPN isolates at different larval stages of $S$. litura (Fig. 5). Host penetration by the nematodes showed a positive correlation with the applied doses of infective juveniles. It was observed that the percentage penetration of infective juveniles ranged from $10-16 \%, 12.65-32 \%$ and $12.51-30 \%$ for $S$. sangi, $H$. indica and $H$. baujardi, respectively, with insignificant difference between them. In contrast, Phan et al. (2005) reported that variation occurred in nematode penetration into $S$. littoralis larvae among differentEPN isolates.
Production of infective juveniles: The reproductive capacity of three EPN isolates were assessed at a concentration of 200 infective juveniles per larva on different larval stages of $S$. litura. Even though all the nematode isolates were highly pathogenic against $S$. litura, successive progeny production failed to occur on $3^{\text {rd }}$ and $4^{\text {th }}$ instar larvae. Similarly, Gokte-Narkhedkar et al. (2019) reported that some species of EPN isolates failed to reproduce successively inside larvae of $S$. litura and concluded that phase change of bacterial symbionts as reason of primary failure. In contrast, Safdar et al. (2018) have reported successive reproduction of $H$. bacteriophora inside different larval stages of $S$. litura larvae $\left(2^{\text {nd }}, 3^{\text {rd }}, 4^{\text {th }}\right.$ and $5^{\text {th }}$ instar larvae). In addition, Han and Ehlers (2001) concluded that lack of important nutrients in host and/or failure of toxins production in phase II bacterial symbiont may not affect development of $H$. bacteriophora. It is therefore suggested that further study on the impact of phase variation of the symbiotic bacteria on the nematode reproduction is necessary.

In the case of $5^{\text {th }}$ instar larvae, successive nematode reproduction was recorded for $S$. sangi and $H$. indica where they produced 57192.86 and 72231.13 infective juveniles per cadaver of larva, respectively (Fig. 6). The reproduction potential of EPNs inside the $5^{\text {th }}$ instar larvae of $S$. litura showed significant variations between $S$. sangi and $H$. indica $(F=1.125 ; d f=1,14 ; P<0.05)$. High production of infective juveniles by $H$. indica may be attributed to the hermaphroditic nature of heterorhabditids and smaller size of infective juveniles. The difference in size and behaviour of isolated nematode species may determine the 
Table 1: $L C_{50}$ values of EPN isolates against $3^{\text {rd }}, 4^{\text {th }}$ and $5^{\text {th }}$ instar larvae of $S$. litura

\begin{tabular}{llllllllll}
\hline \multirow{2}{*}{$\begin{array}{l}\text { Hours of } \\
\text { incubation }\end{array}$} & \multicolumn{7}{c}{ LC $_{50}$ (infective juveniles per larva) } \\
\cline { 2 - 10 } & \multicolumn{7}{c}{ S. sangi } & \multicolumn{7}{c}{ H. indica } \\
\cline { 2 - 10 } & $3^{\text {td }}$ instar & $4^{\text {th }}$ instar & $5^{\text {th }}$ instar & $3^{\text {rd }}$ instar & $4^{\text {th }}$ instar & $5^{\text {th }}$ instar & $3^{\text {rd }}$ instar & $4^{\text {th }}$ instar & $5^{\text {th }}$ instar \\
\hline 24 & 114.07 & 182.8 & 995.7 & 121.19 & 189.53 & 1003.3 & 129.84 & 193.08 & 1016.2 \\
48 & 9.2 & 55.58 & 350.65 & 16.37 & 60.43 & 369.28 & 17.04 & 61.35 & 354.69 \\
72 & - & - & - & - & & - & - & - & - \\
96 & - & - & - & - & - & - & - & - & - \\
120 & - & - & - & - & - & - & - & - & - \\
\hline
\end{tabular}

Table 2: $\mathrm{LT}_{50}$ values of EPN isolates against $3^{\text {rd }}, 4^{\text {th }}$ and $5^{\text {th }}$ instar larvae of $S$. litura

\begin{tabular}{|c|c|c|c|c|c|c|c|c|c|}
\hline \multicolumn{5}{|c|}{ Concentrations } & \multicolumn{5}{|l|}{$\mathrm{LT}_{50}(\mathrm{hr})$} \\
\hline \multirow{2}{*}{$\begin{array}{l}\text { Infective } \\
\text { juveniles } \\
\text { per larva }\end{array}$} & \multirow[b]{2}{*}{$3^{\text {rd }}$ instar } & \multicolumn{2}{|l|}{ S. sangi } & \multicolumn{3}{|c|}{ H. indica } & \multicolumn{3}{|c|}{ H. baujardi } \\
\hline & & $4^{\text {th }}$ instar & $5^{\text {th }}$ instar & $3^{\text {rd }}$ instar & $4^{\text {th }}$ instar & $5^{\text {th }}$ instar & $3^{\text {rd }}$ instar & $4^{\text {th }}$ instar & $5^{\text {th }}$ instar \\
\hline 10 & 57.88 & 59.36 & 88.77 & 59.36 & 59.93 & 91.89 & 60.75 & 59.96 & 90.15 \\
\hline 25 & 49.08 & 54.71 & 83.63 & 50.01 & 55.14 & 87.2 & 50.57 & 56.58 & 85.97 \\
\hline 50 & 24.52 & 34.13 & 74.69 & 25.36 & 36.81 & 77.2 & 28.06 & 37.43 & 74.65 \\
\hline 100 & - & 25.36 & 59.05 & - & 25.7 & 63.3 & 6.63 & 27.43 & 61.32 \\
\hline 200 & - & 12.85 & 42.29 & - & 14.037 & 51.53 & - & 17.7 & 45.19 \\
\hline 400 & - & - & 36.81 & - & - & 43.47 & - & - & 39.93 \\
\hline 800 & - & - & - & - & - & - & - & - & 35.26 \\
\hline
\end{tabular}

successful reproductive ability of nematodes in the host (Loya and Hower, 2003). Likewise, the reproductive potential of six isolates of Steinernema thermophilium on S. littoralis was $19 \times 10^{3}$ to $47 \times 10^{3}$ infective juveniles per larva (Phan et al., 2005). Safdar et al. (2018) reported that $H$. bacteriophora was capable of successful reproduction 25786, 17500, 12642 and 9652 infective juveniles on $5^{\text {th }}, 4^{\text {th }}, 3^{\text {rd }}$ and $2^{\text {nd }}$ instar larvae of $S$. litura. Also, successful reproduction of EPN on larvae of $S$. litura was reported by Park et al. (2001) recording higher multiplication rate in heterorhabditidae, with highest multiplication in the $5^{\text {th }}-6^{\text {th }}$ instar (1.3 × $10^{6}$ infective juveniles per larva). However, Phan et al. (2005) reported that $S$. sangi was capable of successive multiplication inside larvae of $G$. mellonella but failed to do so on larvae of S. litura. Similarly, Ali et al. (2008) have documented variations in production of infective juveniles for EPNs on host insects (Hemicoverpa armigera, Galleria melonella and Corcyra cephalonica). Differences in pathogenicity and reproduction potential among EPN isolates may be attributed to species variation, susceptibility of host, symbiotic bacteria and ecological characteristics ofEPN. EPN have been successively used against some of the agricultural pests and represent good candidate for component of IPM (Lacey and Georgis, 2012).

The future of human deeply relies on sustainability of agriculture system. Meanwhile, the harmful effects that chemical pesticides can impose on human and non-targeted organisms indirectly leads to unsustainable agricultural cropping system. To lessen the environmental pressure from the use of conventional insecticides, more approach on safer pest management strategy need to be imposed. Indigenous isolates of EPN are considered more effective than exotic species for pest control in the local environment (Bedding, 1990). So far, two species of EPN, S. sangi and $H$. baujardi were reported from Mizoram (Lalramnghaki et al., 2017; Vanlalhlimpuia et al., 2018), and the present assessment of their efficacy against insect pest will contribute to enhancement of biological control method of the region in future.

In conclusion, all the three species of locally isolated EPNs showed high pathogenicity against $S$. litura, capable of causing high rate of mortality in all the selected larval stages which indicated that they are good candidates to be included in the integrated pest management.

\section{Acknowledgments}

We are grateful to the Department of Biotechnology, Government of India for financial support to Institutional Advance Level Biotech Hub (BT/22/ NE/2011, Dated: July 19, 2017). We are thankful to the Principal, Pachhunga University College; Head, Department of Zoology, Pachhunga University College for providing the necessary research facilities to carry out this work; and Directorate of Agriculture (Research and Extensions), Government of Mizoram, Aizawl for providing biological samples for the experiment. 


\section{References}

Ahmad, M., M.I. Arif and M. Ahmad: Occurrence of insecticide resistance in field population of Spodoptera litura (Lepidoptera: Noctuidae) in Pakistan. Crop Prot., 26, 807-809 (2007a).

Ahmad, M., A.H. Sayyed, N. Crickmore and M.A. Saleem: Genetics and mechanism of resistance to deltamethrin in a field population of Spodoptera litura (Lepidoptera: Noctuidae) in Pakistan. Pest Manage. Sci., 63, 1002-1010 (2007b).

Ahmad, M., A.H. Sayyed, M.A. Saleem and M. Ahmad: Evidence for field evolved resistance to newer insecticides in Spodoptera litura (Lepidoptera: Noctuidae) from Pakistan. Crop Prot., 27, 1367-1372 (2008).

Ali, S.S., M. Pervez, M. Abid Hussain and R. Ahmad: Susceptibility of three lepidopteran pests to five entomopathogenic nematodes and in-vivo mass production of these nematodes. Arch. Phytopathol. Plant Prot., 41, 300-304 (2008).

Armes, N.J., J.A. Wightman, D.R. Jadhav and G.V. Ranga Rao: Status of insecticide resistance in Spodoptera litura in Andhra Pradesh, India. Pestic. Sci., 50, 240-248 (1997).

Bedding, R.A. and R.J. Akhurst: A simple technique for the detection of insect parasitic rhabditid nematodes in soil. Nematologica, 21, 109-110 (1975).

Bedding, R. and A. Molyneux: Penetration of insect cuticle by infective juveniles of Heterorhabditis spp. (Heterorhabditidae: Nematoda). Nematologica, 28, 354-359 (1982).

Bedding, R.A.: Logistics and strategies for introducing entomopathogenic nematode technology in developing countries. In: Entomopathogenic Nematodes in Biological Control (Eds.: R. Gaugler and H.K. Kaya). CRC Press, Boca Raton, FL., pp. 233-248 (1990).

Boemare, N.: Taxonomy and Systematics. In: Entomopathogenic Nematology (Ed.: R. Gaugler). CABI, New York, pp. 35-56 (2002).

Brixey, J.M.: Forest. Comm. Res. Inf. Note, 273, 1-6 (1997).

CABI: Spodoptera litura. In: Invasive Species Compendium. Wallingford, UK: (2019) CAB International.

Choudhary, A.K. and S.K. Srivastava: Efficacy and economics of some neem-based products against tobacco caterpillar, Spodoptera litura F. on soybean in Madhya Pradesh, India. Int. J. Agric. Sci., 3, 15-17 (2007).

Dhir, B.C., H.K. Mohapatra and B. Senapati: Assessment of crop loss in groundnut due to tobacco caterpillar, Spodoptera litura (F.). Indian J. Plant Protect., 20, 215-217 (1992).

Dowds, B.C.A. and A. Peters: Virulence mechanisms. In: Entomopathogenic Nematology (Ed.: R. Gaugler) CABI Publishing, Wallingford, UK, pp. 79-98 (2002).

Feakin, S.D.: Pest control in groundnuts. PANS Manual No. 2. London, UK, ODA(1973).

Fuxa, J.R., A.R. Richter and F. Agudelo-Silva: Effect of host age and nematode strain on susceptibility of Spodoptera frugiperda to Steinernema feltiae. J. Nematol., 20, 91-95 (1988).

Gaugler, R.: Ecological considerations in the biological control of soilinhabiting insects with entomopathogenic nematodes. Agric. Ecosyst. Environ., 24, 351-360 (1988).

Gedia, M.V., H.J. Vyas, M.F. Acharya and P.V. Patel: Life table, rate of increase and stable age distribution of Spodoptera litura (Fabricius) on cotton. Ann. Plant Prot. Sci., 16, 62-65 (2008).

Georgis, R., A.M. Koppenhöfer, L.A. Lacey, G. Bélair, L.W. Duncan, P.S. Grewal, M. Samish, L. Tan, P. Torr and R.W H.M. van Tol:
Successes and failures in the use of parasitic nematodes for pest control. Biol. Contl., 38, 103-123 (2006).

Grewal, P.S. and R. Georgis: Entomopathogenic nematodes. In: Methods in Biotechnology. Biopesticides: Use and Delivery (Eds.: F. R. Hall and J. J. Menn). Vol. 5, Humana Press, Totowa, NJ, pp. 271-299 (1999).

Grewal, P.S.: Formulation and Application Technology. In: Entomopathogenic Nematology (Ed.: R. Gaugler). CABI Publishing, Wallingford, UK, pp. 265-287 (2002).

Gokte-Narkhedkar, N., K. Bhanare, P. Nawkarkar, P. Chilliveri, B.B. Fand and S. Kranthi: Parasitic potential of entomopathogenic nematode Heterorhabditis indica against two Lepidopteran insect pests of cotton, Helicoverpa armigera (Hubner) and Spodoptera litura (Fabricious). Phytoparasitica, 47, 31-41 (2019).

Han, R. and R.U. Ehlers: Effect of Photorhabdus luminescens phase variants on the in-vivo and in-vitro development and reproduction of the entomopathogenic nematodes Heterorhabditis bacteriophora and Steinernema carpocapsae. FEMS Microbiol. Ecol., 35, 239-247 (2001).

Hominick, W.M., A.P. Reid, D.A. Bohan and B.R. Briscoe: Entomopathogenic nematodes - biodiversity, geographical distribution and the convention on biological diversity. Biocont. Sci. Tech., 6, 317-331 (1996).

Hominick, W.M.: Biogeography. In.: Entomopathogenic Nematology (Ed.: R. Gaugler). CABI Publishing, Wallingford, UK, pp. 115-143 (2002).

Isman, M.B., C.M. Machial, S. Miresmailli and L.D. Bainard: Essential oilbased pesticides: New insights from old chemistry. In: Pesticide Chemistry (Eds.: H. Ohkawa and H. Miyagawa). Wiley-VCH, Weinheim, Germany, p. 113 (2007).

Kaya, H.K.: Soil Ecology. In: Entomopathogenic Nematodes in Biological Control (Eds.: R. Gaugler and H.K. Kaya). CRC Press, Boca Raton, FL., pp. 93-115(1990).

Kaya, H.K. and P. Stock: Techniques in insect nematology. In: Manual of Techniques in Insect Pathology (Ed.: L.A. Lacey) Academic Press, San Diego, pp. 281-324 (1997).

Kerns, D.L., J.C. Palumbo and T. Tellez: Resistance of field strains of beet armyworm (Lepidoptera: Noctuidae) from Arizona and California to carbamate insecticides. J. Econ. Ent., 91, 1038-1043 (1998).

Kranthi, K.R., D.R. Jadhav, R.R. Wanjari, S.S. Ali and D.A. Russell: Carbamate and organophosphate resistance in cotton pests in India, 1995-1999. Bull Entomol. Res., 91, 37-46 (2002).

Kranz, J., H. Schumutterer and W. Koch (Eds.): Diseases Pests and Weeds in Tropical Crops. Berlin and Hamburg, Germany. Verlag Paul Parley (1977).

Lacey, L.A. and R. Georgis: Entomopathogenic nematodes for control of insect pests above and below ground with comments on commercial production. J. Nematol., 44, 218-225 (2012).

Lalramnghaki, H.C., Vanlalhlimpuia, Vanramliana, Lalramliana: Characterization of a new isolate of entomopathogenic nematode, Steinernema sangi (Rhabditida, Steinernematidae), and its symbiotic bacteria Xenorhabdus vietnamensis ( $\mathrm{y}$-Proteobacteria) from Mizoram, north-eastern India. J. Parasit. Dis., 41, 1123-1131 (2017).

Lewis, E.E., J.F. Campbell, C.T. Griffin, H.K. Kaya and A. Peters: Behavioral ecology of entomopathogenic nematodes. Biol. Control, 38, 66-79 (2006).

Lohar, M.K. and Y.M. Nahyoon: Comparative efficacy of hostathion, Sumicidin and Sevin XLR against cotton bollworms Sarhad. $J$. Agric., 11, 363-368 (1995). 
Loya, L.J. and A.A. Hower Jr.: Infectivity and reproductive potential of the Oswego strain of Heterorhabditis bacteriophora associated with life stages of the clover root curculio, Sitona hispidulus. J. Invertebr. Pathol., 83, 63-72 (2003).

Park, S.H., Y.S. Yu and J.S. Park: Biological control of tobacco cutworm, Spodoptera litura Fabricius with entomopathogenic nematodes. Biotechnol. Bioprocess Eng., 6, 139-143 (2001).

Patil, R.K., G. Ravishankar, I.M. Mannikeri, K. Giriraj and S.G. Rayar: Effect of sowing time on production potential and incidence of Spodoptera litura on groundnut cultivars. J. Oilseeds Res., 13, 18-21 (1996).

Phan, K.L., N.C. Nguyen and M. Moens: Steinernema sangi sp. n. (Rhabditida: Steinernematidae) from Vietnam. Russ. J. Nematol., 9, 1-7 (2001).

Phan, K.L., S.A. Subbotin, N.C. Nguyen and M. Moens: Heterorhabditis baujardi sp. n. (Rhabditida: Heterorhabditidae) from Vietnam and morphometric data for $\mathrm{H}$. indica populations. Nematology, 5, 367-382 (2003).

Phan, K.L., L. Tirry and M. Moens: Pathogenic potential of six isolates of entomopathogenic nematodes (Rhabditida: Steinernematidae) from Vietnam. BioControl, 50, 477-491 (2005).

Poinar, G.O. Jr.: Nematodes for biological control of insects. CRC Press, Boca Raton, p. 270 (1979).

Poinar, G.O. Jr.: Taxonomy and biology of Steinernematidae and Heterorhabditidae. In: Entomopathogenic Nematodes in Biological Control (Eds.: R. Gaugler and H.K. Kaya). CRC Press, Boca Raton, FL, pp. 23-61 (1990).

Poinar, G.O. Jr., G.K. Karunakar and H. David: Heterorhabditis indicus n. sp. (Rhabditida: Nematoda) from India: Separation of Heterorhabditis spp. by infective juveniles. Fundam. Appl. Nematol., 15, 467-472(1992).

Punithavalli, M., A.N. Sharma and R.M. Balaji: Seasonality of the common cutworm Spodoptera litura in a soybean ecosystem. Phytoparasitica, 42, 213-222 (2014).

Qing, H.G., D.D. Wang, J. Ding, R.H. Huang and Z.X. Ye: Host plants of Spodoptera litura. ActaAgr. Jiangxi., 18, 51-59 (2006).

Rao, G.V.R., J.A. Wightman and D.V. Ranga Rao: World review of the natural enemies and diseases of Spodoptera litura (F.) (Lepidoptera: Noctuidae). Insect Sci. Appl., 14, 273-284 (1993).

Safdar, H., N. Javed, S. A. Khan and M. Arshad: Reproduction potential of entomopathogenic nematodes on armyworm (Spodoptera litura). Pak. J. Zool., 50, 771-774 (2018).

Saleem, M.A., M. Ahmad, H.A. Sayyed and M. Aslam: Resistance to selected organochlorine, carbamate and pyrethroid in Spodoptera litura (Lepidoptera: Noctuidae) from Pakistan. J. Econ. Entomol., 101, 1667-1675 (2008).

Satyagopal, K., S.N. Sushil, P. Jeyakumar, G. Shankar, O.P. Sharma, D.R. Boina, R. Varshney, S.K. Sain, B.S. Sunanda, Ram Asre, K.S. Kapoor, S. Arya, S. Kumar, C.S. Patni, C. Chattopadhyay, A. Krishnamurthy, U. Devi, K. Rao, M. Vijaya, K. Sireesha, Madhavilatha, S. Sreedharan, R.P. Chandel, Y.S. Kotikal, J. Halder and S. Saha: AESA based IPM package for Chillies/Capsicum. p. 46 (2014).

Shapiro-llan, D.I., R. Gaugler, W.L. Tedders, I. Brown and E.E. Lewis: Optimization of inoculation for in vivo production of entomopathogenic nematodes. J. Nematol., 34, 343-350 (2002a).

Sharma, A.N., G.K. Gupta, R.K. Verma, O.P. Sharma, S. Bhagat and N. Amaresan: Integrated Pest Management Package for Soybean. Faridabad (India): Directorate of Plant Protection, Quarantine and Storage. p. 41 (2014)

Simões, N. and J.S. Rosa: Pathogenicity and host specificity of entomopathogenic nematodes. Biocontrol Sci. Technol., 6 403-411 (1996).

Singh, S.P. and S.K. Jalali: Proceedings of the National Scientists Forum on Spodoptera litura (F.). In: Spodoptera litura in India (Eds.: J.A. Wightman and G.V. Ranga Rao). ICRISATAsia (1997).

Vanlalhlimpuia, Lalramliana, H.C. Lalramnghaki and Vanramliana: Morphological and molecular characterization of entomopathogenic nematode, Heterorhabditis baujardi (Rhabditida, Heterorhabditidae) from Mizoram, North-eastern India. J. Parasit. Dis., 42, 341-349 (2018).

Villani, M.G. and R.J. Wright: Entomogenous nematodes as biological control agents of European chafer and Japanese beetle (Coleoptera: Scarabaeidae) larvae infesting turf grass. J. Econ. Entomol., 81, 484-487 (1988).

Whalon, M., S.D. Mota, R.M. Hollingworth and L. Duynslager: Resistant pest management:Arthropod database (2007).

Wu, C.J., S.Y. Fan, Y.H. Jiang, H.H. Yao and A.B. Zhang: Inducing gathering effect of taro on Spodoptera litura Fabricius. Chin. J. Ecol., 23, 172-174 (2004). 